\title{
KONDISI DAERAH PENANGKAPAN IKAN CAKALANG (KATSUWONUS PELAMIS) DI PERAIRAN LAUT FLORES
}

\author{
Asruddin \\ Program Studi Budidaya Perairan Fakultas IImu-IImu Pertanian Universitas \\ Muhammadiyah Gorontalo Jl. Prof. Dr. Mansoer Pateda, Pentadio Timur, \\ Gorontalo, Indonesia 96212 \\ Email: rudisiago@umgo.ac.id
}

\begin{abstract}
The purpose of this research is to know the distribution fishing ground of skipjack tuna by the fishermen againts the distribution of temperature and CHL-a in the sea of Flores. the distribution fishing ground of skipjack to SPL and CHL-a distribution was analyzed by GIS using ArcGIS 10.2. The research resulted that the distribution fishing ground of skipjack tuna in the sea of Flores especially in Bulukumba Regency is in the less potential area because it is not on the thermal front (the fishing grounds that estimated have thermal fronts are at a temperature gradient of $\left.0,5^{\circ} \mathrm{C}\right)$.
\end{abstract}

Keywords: GIS, Distribution of Catching Areas, Skipjack Fish

\section{Abstrak}

Tujuan penelitian ini adalah untuk mengetahui distribusi tempat penangkapan ikan cakalang oleh nelayan terhadap distribusi suhu dan CHL-a di laut Flores. distribusi pancing dari cakalang ke distribusi SPL dan CHL-a dianalisis oleh SIG menggunakan ArcGIS 10.2. Hasil penelitian menunjukkan bahwa distribusi tempat penangkapan ikan cakalang di laut Flores khususnya di Kabupaten Bulukumba berada pada daerah yang kurang potensial karena tidak berada di bagian depan termal (daerah penangkapan ikan yang diperkirakan memiliki front termal berada pada gradien suhu $0,50 \mathrm{C}$ ).

Kata Kunci : GIS, Distribusi Daerah Penagkapan,Ikan Skipjack

\section{PENDAHULUAN}

Berdasarkan wilayah Pengelolaan Perikanan Republik Indonesia (WPP. RI 713) yaitu Perairan Teluk Bone, Perairan laut Bali dan Perairan laut Flores sementara itu menurut Komisi Nasional Pendugaan Stok Ikan Laut Lembaga IImu Pengetahuan indonesia mempunyai luas $605.300 \mathrm{~km}^{2}$, dengan potensi biomas dan potensi lestari ikan cakalang sebesar 56.888 ton dan 28.449 ton pertahun dengan indeks kelimpahan $94 \mathrm{~kg} / \mathrm{km}^{2}$.

Ikan cakalang merupakan komoditas penting yang memilki nilai ekonomis dan ditangkap oleh nelayan dengan menggunakan bermacammacam alat tangkap seperti pancing pole and line), pancing tangan (hand 
line), pancing tonda (trolling line), dan kadang dengan pukat cincin (purse seine), dan jaring insang (drift surface gill net). Penggunaan berbagai macam alat tangkap tersebut cenderung akan menyebabkan tekanan terhadap populasi ikan cakalang ditandai dengan ukuran ikan cakalang yang tertangkap semakin kecil ukurannya.

Telah banyak dilakukan penelitian mengenai daerah penangkapan ikan seperti Zainuddin $\mathrm{M}$ (2009), meneliti tentang Estimasi potensi dan pemetaan daerah potensial penangkapan ikan pelagis di perairan Selayar dengan menggunakan citra satelit aqua/modis. Zainuddin.M. dkk (2013), meneliti karakterisasi zona potensial perikanan cakalang selama monsoon tenggara di perairan Bone dan Laut Flores menggunakan penginderaan jauh data kelautan. Berdasarkan uraian di atas maka penulis melakukan penelitian mengenai sebaran daerah penangkapan ikan cakalang oleh nelayan terhadap sebaran suhu dan CHL-a di Perairan Laut Flores.

\section{METODE PENELITIAN}

\section{Metode pengumpulan data}

$$
\text { Jenis data yang digunakan }
$$
dalam penelitian ini dengan menggunakan data sekunder dan data primer. Data primer menggunakan data posisi lintang bujur keberadaan serta sebaran kapal-kapal penangkap ikan cakalang sedangkan data sekunder adalah data suhu dan data chl-a. Teknik pengambilan data primer yaitu dengan mengikuti kegiatan operasi penangkapan ikan serta menggunakan kuisioner terhadap nelayan yang melakukan penangkapan ikan cakalang di di perairan laut flores wilayah sekitar perairan Kabupaten Selayar dan perairan di Kabupaten Bulukumba. Sedangkan pengambilan data sekunder dengan menggunakan data citra satelit dengan mendownload data sebara suhu dan clorofil-a

\section{Analisis kondisi daerah penangkapan}

Data posisi lintang dan bujur daerah penangkapan dimasukkan ke dalam website colorado center for astrodynamics research (CCAR), untuk mengetahui penyebaran suhu permukaan laut dan klorofil-a dari satelit Aqua MODIS menggunakan Global MODIS SST Viewer dan Global MODIS Color Viewer pada resolusi 4 $\mathrm{km}$ dan data dikomposit sebanyak 14 hari kemudian di overley dalam 3 bulan atau permusim untuk menganalisis tingkat SPL dan $\mathrm{CHL}-\mathrm{a}$ daerah penangkapan ikan cakalang dengan menggunakan Sea DAS. Analisis yang digunakan dalam membuat peta penyebaran alat tangkap ikan cakalang serta menganalisis tingkat SPL dan CHL-a menggunakan analisis GIS dengan software arcgis 10.2 .

\section{HASIL DAN PEMBAHASAN}

Jenis Berdasarkan data suhu permukaan laut (SPL) dan data klorofil-a pada musim peralihan timurbarat, musim barat dan musim peralihan barat-timur di perairan laut Flores dapat dilihat sebagai berikut: 


\section{Peta daerah penangkapan ikan cakalang pada musim peralihan timur barat}

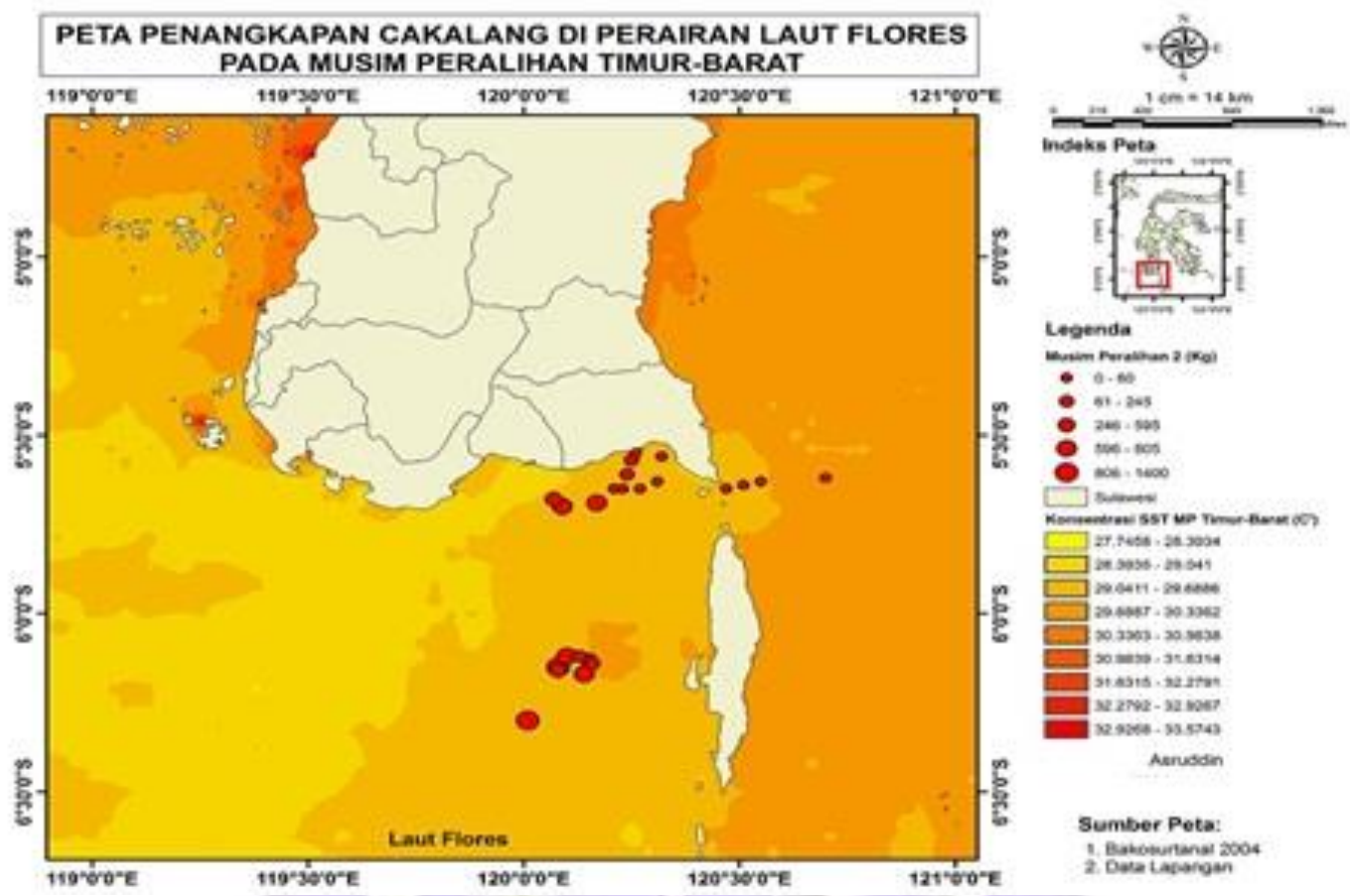

Gambar 1. Sebaran SPL dan sebaran posisi daearah penangkapan ikan cakalang oleh nelayan pada musim peralihan Timur-Barat

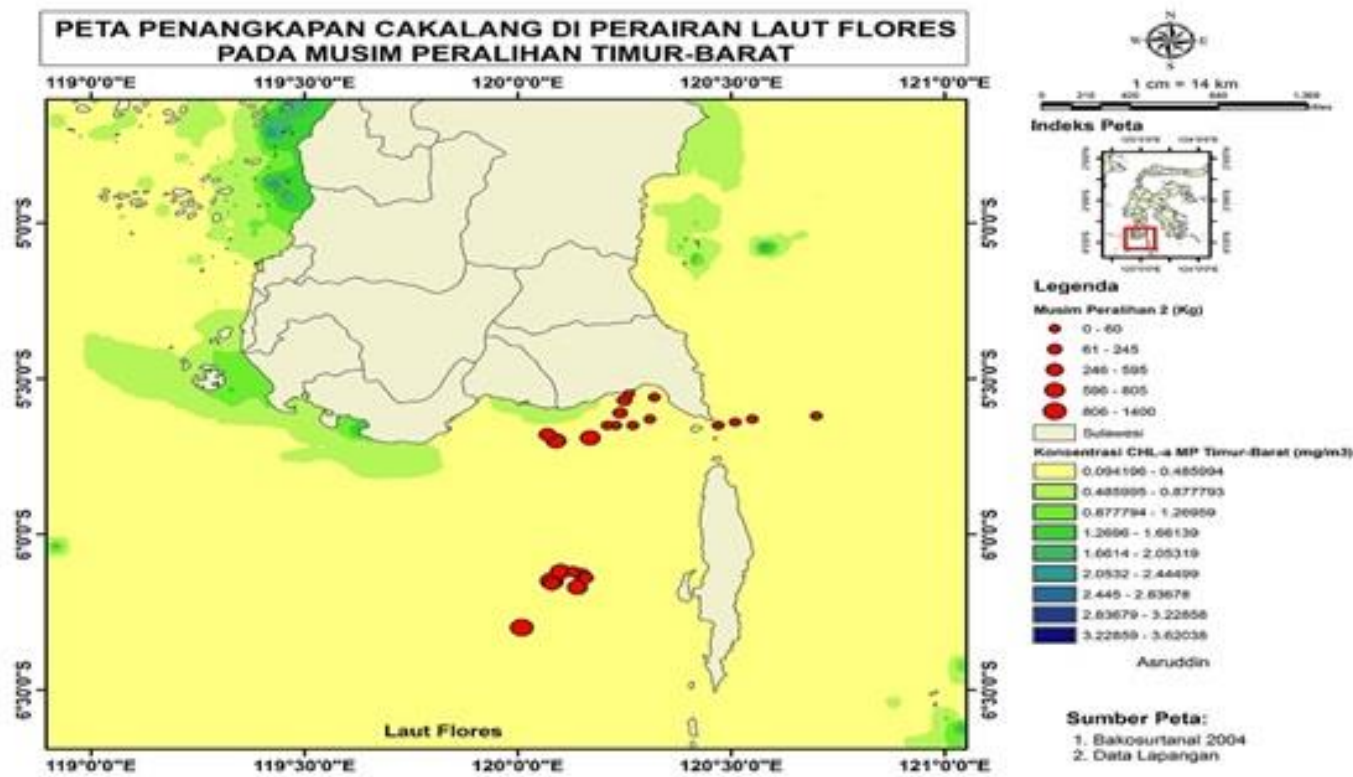

Gambar 2. Sebaran CHL-a dan sebaran posisi daearah penangkapan ikan cakalang oleh nelayan pada musim peralihan Timur-Barat 
2. Peta daerah penangkapan ikan cakalang pada musim barat

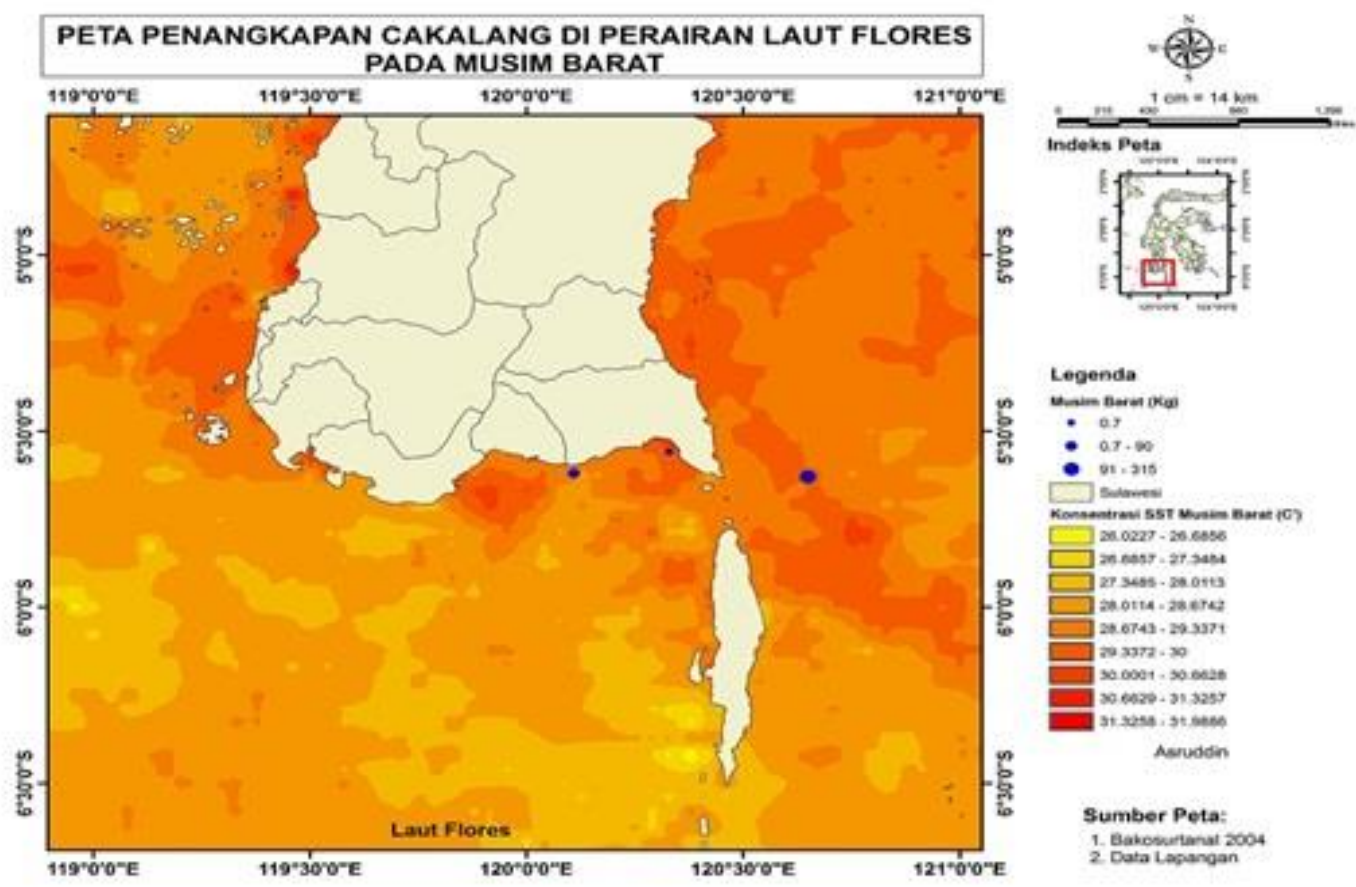

Gambar 3. Sebaran SPL dan sebaran posisi daearah penangkapan ikan cakalang oleh nelayan pada musim Barat

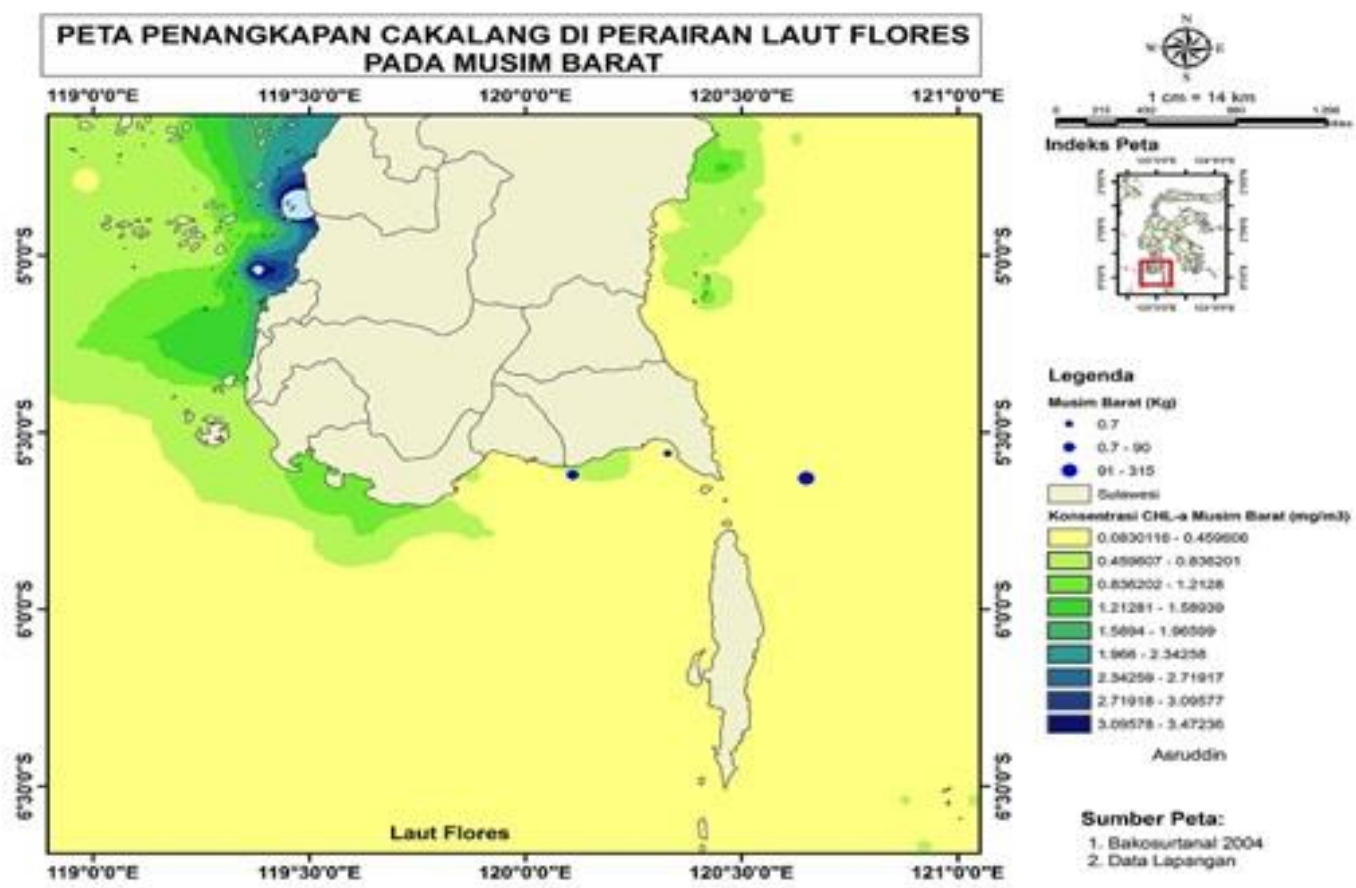

Gambar 4. Sebaran CHL-a dan sebaran posisi daearah penangkapan ikan cakalang oleh nelayan pada musim Barat 
3. Peta daerah penangkapan ikan cakalang pada musim peralihan barat timur

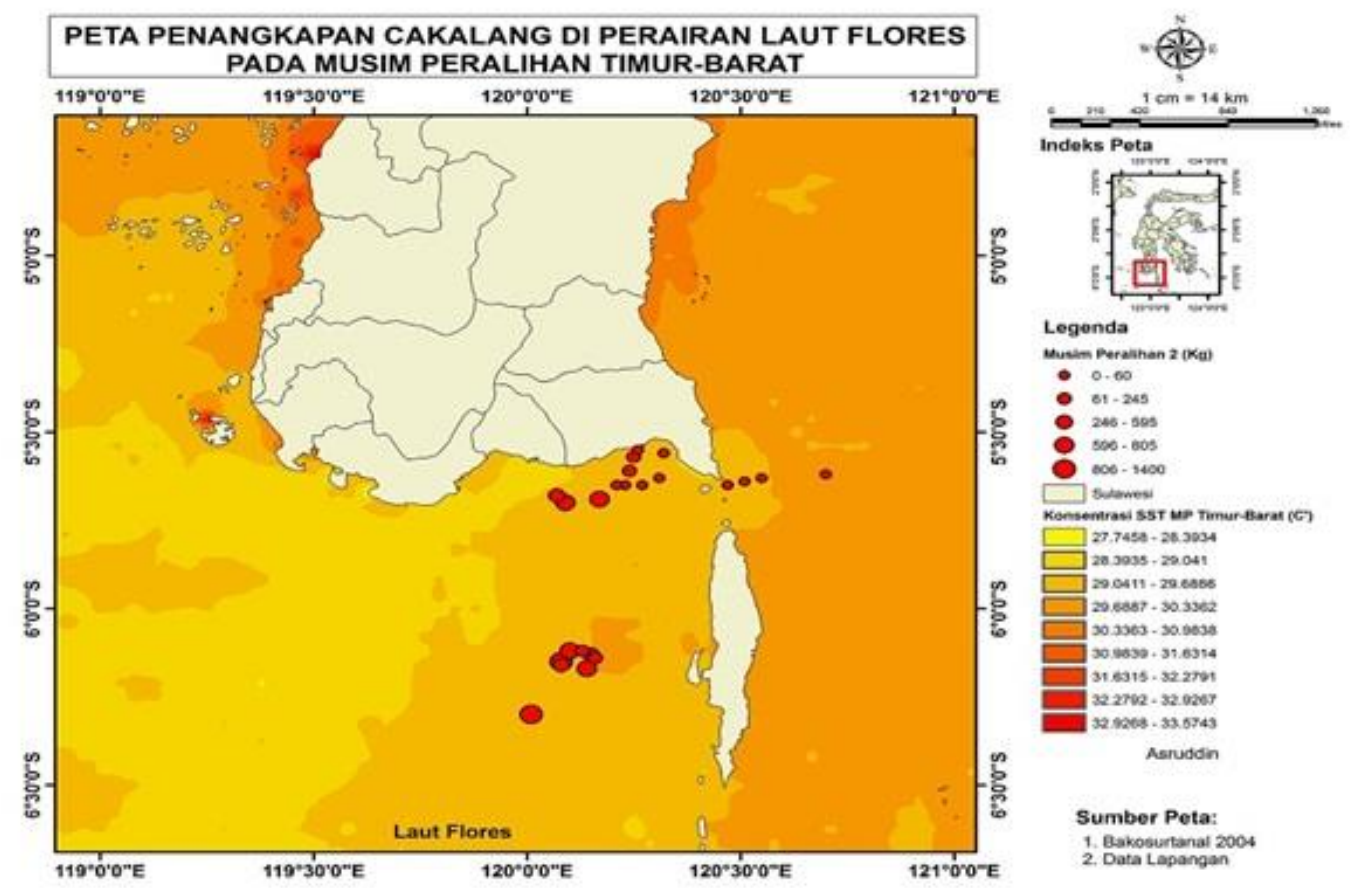

Gambar 5. Sebaran SPL dan sebaran posisi daearah penangkapan ikan cakalang oleh nelayan pada musim peralihan Barat-Timur

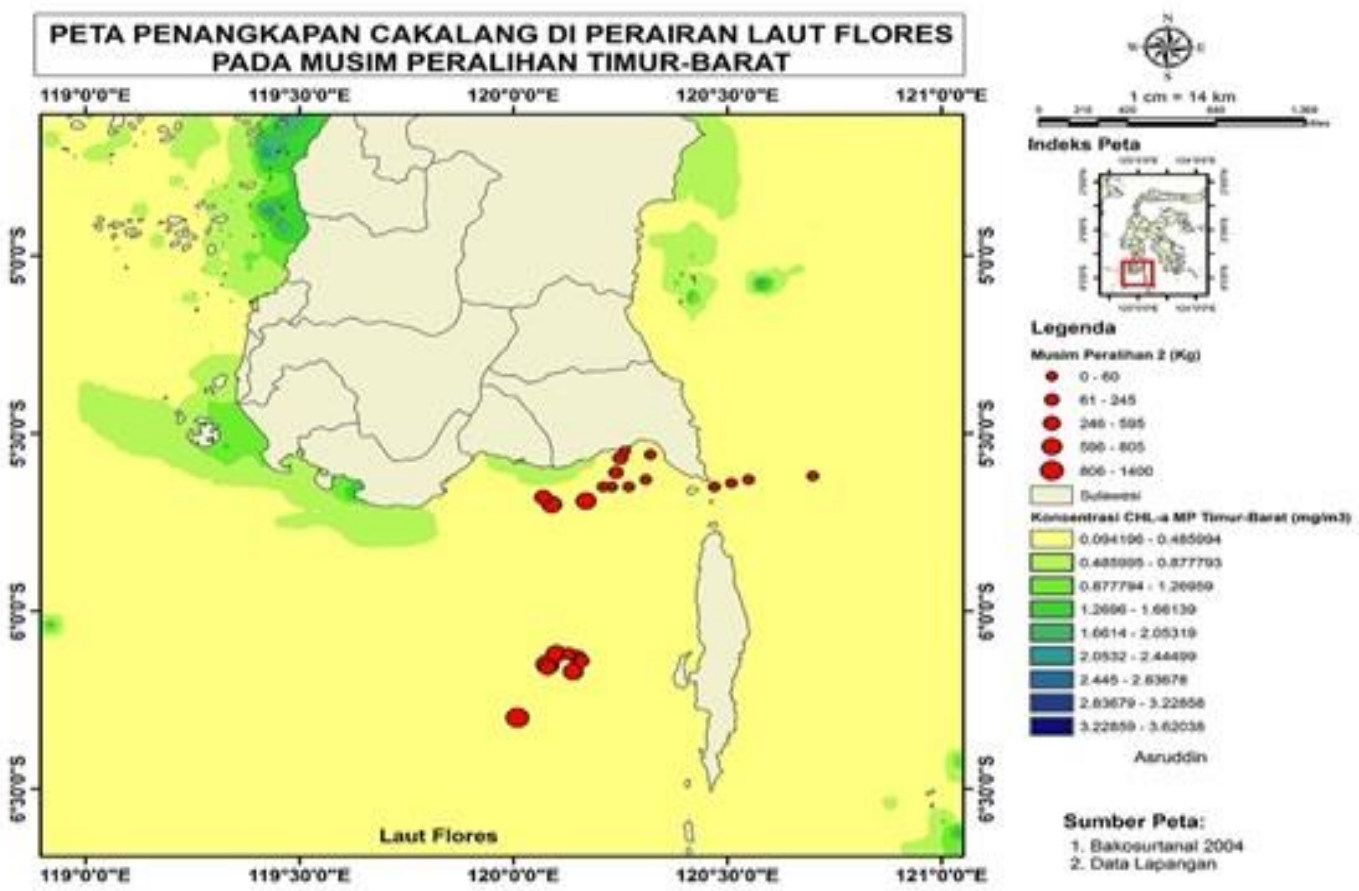

Gambar 6. SebaranCHL dan sebaran posisi daearah penangkapan ikan cakalang oleh nelayan pada musim peralihan Barat-Timur 
Konsentrasi suhu permukaan laut dan klorofil-a pada peralihan Musim timur barat (bulan September, Oktober dan November)

Daerah penangkapan ikan cakalang di perairan Laut Flores oleh nelayan di Bulukumba (purse seine plus rumpon, purse seine non rumpon dan gill net) berada pada kisaran SPL $28.39^{\circ} \mathrm{C}-30.33^{\circ} \mathrm{C}$. Lihat Gambar 1. hasil tangkapan terbesar berada di sebelah barat perairan selayar dimana kisaran SPL berkisar 29.04 sampai $30.33{ }^{\circ} \mathrm{C}$. sedangkan CHL-a pada daerah penangkapan ikan cakalang oleh nelayan berada pada kisaran CHL-a 0.09 sampai $0.48 \mathrm{mg} \mathrm{m}^{-3}$.

Pada Musim Peralihan Timur Barat, perairan laut flores sekitar kabupaten bulukumba cenderung memiliki perairan yang tidak terlalu berombak sehingga kegiatan penangkapan pada musim itu mengalami peningkatan jumlahnya. Kapal-kapal purse seine yang menggunakan alat bantu rumpon masih memaksimalkan kegiatan penangkapan ikan cakalang di area rumpon.

Terlihat bahwa penyebaran daerah penangkapan ikan cakalang yang menggunakan alat bantu rumpon, berada pada sebelah barat kabupaten Kepulauan Selayar dan sebelah selatan Kabupaten Bulukumba hal ini dapat ditandai dari jarak fishing base dan fishing ground yang berjauhan. Pada daerah penangkapan yang melakukan pengejaran ikan cakalang atau kapal purse seine aktif berada pada daerah yang tidak terlalu jauh dari fishing base yaitu hanya berada pada daerah sekitar perairan Bira Kabupaten Bulukumba.
Konsentrasi suhu permukaan laut dan klorofil-a pada Musim barat (bulan Desember, Januari dan Februari )

Daerah penangkapan ikan cakalang pada musim barat di perairan Laut Flores oleh nelayan di Bulukumba (purse seine plus rumpon, purse seine non rumpon dan gill net) berada pada kisaran SPL $28.01{ }^{\circ} \mathrm{C}-30{ }^{\circ} \mathrm{C}$, Lihat gambar3. Hasil tangkapan terbesar berada di sebelah barat perairan Selayar dimana kisaran SPL berkisar $29.33^{\circ} \mathrm{C}-30^{\circ} \mathrm{C}$ sedangkan $\mathrm{CHL}-a$ pada daerah penangkapan ikan cakalang oleh nelayan berada pada kisaran CHL-a 0.08 sampai $0.45 \mathrm{mg} \mathrm{m}^{-3}$ Lihat Gambar 4.

Pada Musim Barat diperairan laut flores memiliki cuaca buruk sehingga terlihat penyebaran daerah penangkapan ikan yang kurang. Jumlah kapal purse seine sangat sedikit yang melakukan penangkapan ikan baik itu purse seine yang menggunakan alatbantu rumpon maupun tanpa menggunakan alat bantu rumpon.

Konsentrasi suhu permukaan laut dan klorofil-a pada Musim peralihan barat timur (bulan Desember, Januari dan Februari)

Pada musim peralihan barattimur memiliki penyebaran daerah penangkapan ikan cakalang hampir sama dengan penyebaran daerah penangkapan ikan pada musim peralihan musim timur-barat. Hal ini dikarenakan bahwa pada musim peralihan cenderung perairan tenang dan tidak berombak sehingga memudahkan nelayan untuk melakukan kegiatan penangkapan ikan. 
Daerah penangkapan ikan cakalang pada musim peralihan barat Timur di perairan Laut Flores oleh nelayan purse seine plus rumpon, purse seine non rumpon dan gill net berada pada kisaran SPL 28.01 sampai $29.97{ }^{\circ} \mathrm{C}$. hasil tangkapan terbesar berada di sebelah barat perairan Selayar dimana kisaran SPL berkisar 29.36 sampai $29.97 \quad{ }^{\circ} \mathrm{C}$ (Gambar 5) sedangkan CHL-a pada daerah penangkapan ikan cakalang oleh nelayan berada pada kisaran SHL-a 0.038 sampai $0.422 \mathrm{mg} \mathrm{m}^{-3}$ (Gambar 6).

Kondisi daerah penangkapan ikan cakalang oleh nelayan di Kabupaten Bulukumba pada alat tangkap purse seine plus rumpon, purse seine non rumpon dan gill net di perairan flores, berada pada kisaran SPL 28.01 sampai $30.33{ }^{\circ} \mathrm{C}$ dan kisaran Klorofil-a antara $0.08 \mathrm{mg} / \mathrm{m}^{3}$ sampai $0.08 \mathrm{mg} \mathrm{m}^{-3}$. Ada empat musim penangkapan ikan cakalang selama satu tahun dan memiliki kondisi Oseanografi yang berbeda setiap tahunnya. Kondisi oceanografi yang meliputi Sea Surface Temperature (SST) dan klorofil-a dan arus dapat digunakan untuk prediksi zona penangkapan ikan yang potensial (Siregar, 2006). Suhu yang ideal untuk ikan cakalang antara 26 sampai $32{ }^{\circ} \mathrm{C}$ dan suhu yang ideal untuk ikan cakalang melakukan pemijahan antara $28{ }^{\circ} \mathrm{C}$ Sampai $29^{\circ} \mathrm{C}$ (Gunarso, 1996).

Kondisi daerah penangkapan ikan cakalang pada musim timur di perairan Laut Flores Berdasarkan data suhu permukaan laut (SPL) antara 29 dan $30^{\circ} \mathrm{C}$ Di sekitar Kepulauan Selayar tampak didominasi oleh SPL dari 29 sampai dengan $29.5^{\circ} \mathrm{C}$ dan relatif lebih rendah dari sekitarnya. Di sekitar kepulauan tersebut cenderung dibatasi oleh SPL $29^{\circ} \mathrm{C}$. Dari informasi peta tersebut ditemukan bahwa Thermal front diduga kuat terjadi pada kontur SPL $28.5^{\circ} \mathrm{C}$. Kepadatan Clorofil-a pada musim timur di Daerah penangkapan ikan cakalang diduga berada pada sebelah barat kepulauan selayar dimana kisaran klorofil berada pada 0.2 hingga $0.3 \mathrm{mg} \mathrm{m}^{-3}$. $\mathrm{Di}$ sebelah selatan tanah beru juga berkisar antara 0.2 hingga $0.3 \mathrm{mg} \mathrm{m}^{-3}$. Disebelah tenggara kepulauan selayar berkisar antara 0.3 sampai $0.4 \mathrm{mg} \mathrm{m}^{-}$ 3.

Kondisi Daerah penangkapan ikan cakalang di perairan Laut Flores oleh nelayan di Bulukumba pada musim peralihan Timur Barat berada pada kisaran SPL $28.39{ }^{\circ} \mathrm{C}-30.33^{\circ} \mathrm{C}$. hasil tangkapan terbesar berada di sebelah barat perairan selayar dimana kisaran SPL berkisar 29.04 sampai $30.33^{\circ} \mathrm{C}$ sedangkan CHL-a pada daerah penangkapan ikan cakalang oleh nelayan berada pada kisaran SHL-a 0.09 sampai $0.48 \mathrm{mg} \mathrm{m}^{-3}$.

Kondisi daerah penangkapan ikan cakalang pada musim barat di perairan Laut Flores oleh nelayan di Bulukumba berada pada kisaran SPL 28.01 sampai $30^{\circ} \mathrm{C}$. hasil tangkapan terbesar berada di sebelah barat perairan selayar dimana kisaran SPL berkisar 29.33 sampai $30{ }^{\circ} \mathrm{C}$ sedangkan $\mathrm{CHL}-\mathrm{a}$ pada daerah penangkapan ikan cakalang oleh nelayan berada pada kisaran SHL-a 0.08 sampai $0.45 \mathrm{mg} \mathrm{m}^{-3}$.

Kondisi daerah penangkapan ikan cakalang pada musim peralihan barat Timur di perairan Laut Flores oleh nelayan purse seine plus rumpon, purse seine non rumpon dan gill net berada pada kisaran SPL 28.01 Sampai $29.97{ }^{\circ} \mathrm{C}$. hasil tangkapan terbesar berada di sebelah barat 
perairan Selayar dimana kisaran SPL berkisar 29.36 sampai $29.97{ }^{\circ} \mathrm{C}$ sedangkan CHL-a pada daerah penangkapan ikan cakalang oleh nelayan berada pada kisaran SHL-a 0.038 sampai $0.422 \mathrm{mg} \mathrm{m}^{-3}$.

Dari uraian di atas dapat disimpulkan bahwa daerah penangkapan ikan cakalang oleh nelayan berada pada daerah yang kurang potensial berdasarkan daerahdaerah yang diperkirakan terjadi termal front dimana berada pada gradient suhu $0,5{ }^{\circ} \mathrm{C}$. Menurut LAPAN (2003) dalam Simbolon, D dan Tajuddin, M (2008), Fenomena timbulnya thermal front dan upwelling dapat dipakai untuk memprediksi daerah penangkapan ikan yang potensial. Daerah thermal front ditandai dengan melihat adanya gradient suhu yang rapat dibaandingkan dengan daerah sekitarnya dengan kisaran suhu $0.5^{\circ} \mathrm{C}$ dalam $3 \mathrm{Km}$ sedangkan menurut Tadjuddah (2005), pola pergerakan front terdapat pada SPL 29.90 sampai $31.30{ }^{\circ} \mathrm{C}$ yang diindikasikan sebagai daerah penangkapan. Dalam penelitian Susaniati (2014) ikan hasil tangkapan ikan cakalang oleh nelayan diperairan laut flores cenderung tidak memenuhi Kriteria layak tangkap.

\section{PENUTUP}

Berdasarkan hasil penelitian mengenai sebaran daerah penangkapan ikan cakalang di perairan Laut Flores oleh nelayan di Kabupaten Bulukumba cenderung berada pada daerah yang kurang potensial karena tidak berada pada daerah termal front (daerahdaerah yang diperkirakan terjadi termal front berada pada gradient suhu 0,50 C).

\section{DAFTAR PUSTAKA}

Gunarso. W, (1996). Tingkah Laku Ikan dan Gill net. Fakultas Perikanan IPB. Bogor. hal. 87

Susaniati, W. 2014. Kajian Biologi Populasi Ikan Cakalang (katsuwonus pelamis) di Perairan Laut Flores Sulawesi Selatan. Tesis. Program Pascasarjana, Universitas Hasanuddin. Makassar.

Siregar.v,.and Harold.J.D. (2006). Identification of Oceanographic Parameters for Determining Pelagic Tuna Fishing ground in the North Papua Waters Using Multi-Sensor Satellite Data. Biotropiavol. 13 NO. : 37 -48.

Simbolon, D., \& Tadjuddah, M. (2008).

Pendugaan Front dan Upwelling Melalui Interpretasi Citra Suhu Permukaan Laut Dan Clorofil-A Di Perairan Wakatobi Sulawesi Tenggara. Buletin PSP, 17(3).

Tadjuddah, M. (2005). Analisis Daerah Penangkapan Ikan Cakalang (Katsuwonus pelamis) dan Madidihan (Thunnus albacores) Dengan Menggunakan Data Satelit Di Perairan Kabupaten Wakatobi Sulawesi Utara. Tesis Sekolah Pascasarjana Institut Pertanian Bogor. Bogor.

Zainuddin, M. (2009). Estimasi Potensi

Dan Pemetaan Daerah Potensial Penangkapan Ikan Pelagis Di Perairan Selayar Dengan Menggunakan Citra Satelit Aqua/Modis. Torani 
(Jurnal IImu Kelautan dan Perikanan) Vol, 19.

Zainuddin, M., Nelwan, A., Farhum, S.

A., Hajar, M. A. I., \& Kurnia,

M. (2013). Characterizing

Potential Fishing Zone of

Skipjack Tuna during the

Southeast Monsoon in the

Bone Bay-Flores Sea Using

Remotely Sensed

Oceanographic

Data. International Journal Of

Geosciences, 4(01), 259. 